\title{
The Comic Media of Folklore for BIPA Learning
}

\author{
Atikah Anindyarini ${ }^{1}$, Sumarwati ${ }^{2}$, Kuhafeesah Rongso ${ }^{3}$ Mila Anggarwati ${ }^{4}$, Moh. Sayful \\ Zuhri $^{5}$ \\ ${ }^{1245}$ Universitas Sebelas Maret, Surakarta, Indonesia \\ ${ }^{5}$ Fatoni University \\ 1atikahanindyarini@gmail.com; 2watik_uns@ymail.com; 3aazalia85@gmail.com, \\ ${ }^{4}$ mohsayfulzuhri@student.uns.ac.id.
}

\begin{abstract}
In this article Narotama Stories will be explained as BIPA teaching material and the use of Narotama story comics as media in BIPA learning. The method used in this research is descriptive qualitative method. Data collection techniques in this study were carried out by means of observation, interviews, documentation, Focus Group Discussion (FGD). Observations in this study were carried out by observing the place or location commonly used to carry out traditional Dhukutan ceremonies in Nglurah Tawangmangu Village. The primary data source in this study was Narotama folklore which was obtained verbally from indigenous people and community leaders in Nglurah Village. Tawangmangu District. A part from interviews, data collection was also carried out through Focus Group Discussions by inviting commmunity leaders, traditional leaders, teachers, education offices, and several communities there for discuuc Narotama's story and the link between the story and the traditional Dhukutan ceremony. The sampling technique was purposive sampling. Data validity testing techniques used are data triangulation and method triangulation. Data analysis uses an interactive analysis model that included data reduction, data presentation, and drawing conclusions and vertification. The use of comic media with foklore material (Narotama Stories) expected to facilitate and motivate BIPA students to learn it.
\end{abstract}

Keyword: BIPA, teaching material, folklore, Narotama Stories, comic media

\section{PENDAHULUAN}

Saat ini, bahasa Indonesia telah mengalami perkembangan yang sangat pesat. Peran bangsa Indonesia dalam pergaulan internasional mampu menempatkan bahasa Indonesia sebagai salah satu bahasa yang dianggap penting di dunia. Hal ini terbukti dengan semakin banyaknya orang asing yang tertarik belajar bahasa Indonesia. Mereka termotivasi belajar bahasa Indonesia dengan berbagai tujuan, baik tujuan politik, perdagangan, seni budaya, dan lainnya. Terlebih lagi dengan diberlakukannya Masyarakat Ekonomi Asean (MEA), hal ini menjadi salah satu penyebab meningkatnya minat orang asing untuk mempelajari bahasa Indonesia. Baik mereka yang ingin mempelajari bahasa Indonesia di Indonesia maupun mereka yang ingin mempelajari bahasa Indonesia di negaranya sendiri.

Di dalam negeri, saat ini tercatat tidak kurang dari 45 lembaga yang telah mengajarkan bahasa Indonesia bagi penutur asing (BIPA). Adapun di luar negeri pengajaran BIPA telah 
dilakukan oleh sekitar 36 negara di dunia. Badan Pengembangan dan Pembinaan Bahasa menyadari bahwa Pengajaran bahasa Indonesia bagi penutur asing (BIPA) mempunyai peran yang sangat penting dalam memperkenalkan Indonesia kepada masyarakat internasional. Hal ini dengan pertimbangan bahwa pengajaran BIPA di samping merupakan media untuk menyebarkan bahasa Indonesia ke kancah internasional, juga untuk memperkenalkan masyarakat dan budaya Indonesia [1].

Seseorang yang mempelajari bahasa suatu negara otomatis akan mempelajari budayanya. Bahasa dan budaya adalah sesuatu yang tidak terpisahkan. Begitupula bagi pemelajar BIPA. Kebudayaan adalah hasil cipta, rasa, karya manusia untuk mendapatkan kesenangan dan kenikmatan hasil akal pemikiran manusia. Unsur yang membentuk kebudayaan menurut [2] ada tujuh, yaitu 1) sistem religi, 2) sistem organisasi kemasyarakatan, 3) sistem pengetahuan, 4) bahasa lisan dan tulisan, 5) kesenian, 6) sistem mata pencarian, dan 7) sistem teknologi dan alat. Menurut Koentjaraningrat, bahasa merupakan bagian dari kebudayaan atau dengan kata lain bahasa itu di bawah lingkungan kebudayaan.

Folklor adalah salah satu hasil dari kebudayaan. Endraswara dalam [3] menjelaskan bahwa kata folklor berasal dari kata folk dan lore, yang mempunyai arti kolektif. Folk bisa diartikan 'rakyat' dan lore diartikan 'tradisi'. Folklor adalah salah satu bentuk/wujud tradisi rakyat. Jadi, foklor merupakan sebagian kebudayaan kolektif yang tersebar dan diwariskan secara turuntemurun.

Penelitian tentang foklor pernah dilakukan oleh [4] dalam pembelajaran menyimak di Sekolah Dasar. Foklor dipilih sebagai subjek penelitian dengan pertimbangan bahwa foklor merupakan cerita yang menarik perhatian anak-anak, sarat dengan pendidikan, serta dapat mengembangkan imajinasi anak-anak.Hasil penelitian tersebut membuktikan bahwa penggunaan folklor sebagai landas tumpu pembelajaran keterampilan menyimak di kelas VA Sekolah Dasar Negeri Dadaha 1 Kota Tasikmalaya mampu meningkatkan daya simak siswa.

Dari penelitian tersebut bisa disimpulkan bahwa pemilihan materi yang menarik akan merangsang minat siswa untuk belajar. Hal ini tentunya berlaku juga dalam pembelajaran BIPA. Menurut [5], permasalahan yang sering muncul dalam pembelajaran BIPA bersumber pada pembelajaran bahasa Indonesia yang semata-mata mengacu pada belajar tentang tatabahasa dan kosa kata. Hal inilah yang menjadikan pengajaran BIPA kurang lengkap, sehingga perlu adanya pengintegrasian tentang budaya dalam pengajaran BIPA. Dengan demikian, adanya integrasi budaya ke dalam pengajaran BIPA tentunya akan merangsang minat mereka untuk belajar. Karena pada dasarnya, pembelajar BIPA sangat antusias ketika mereka mengenal dan mempelajari budaya Indonesia.

Selain dengan memilih materi yang menarik, pemilihan media yang tepat akan merangsang pemelajar BIPA lebih termotivasi untuk belajar. Komik adalah salah satu media belajar yang bisa menarik siswa untuk belajar, hal ini tentunya berlaku juga bagi pemelajar BIPA.

Relevan dengan pernyataan tersebut, maka pemanfaatan media komik dalam materi cerita rakyat diharapkan bisa mempermudah pemelajar BIPA untuk memahami cerita rakyat Dhukutan. Untuk itu, dalam penulisan artikel ini akan dipaparkan tentang Cerita Narotama (Cerita Rakyat Dhukutan) dan bagaimana pemanfaaatan media komik bermuatan cerita rakyat (Cerita Narotama /Cerita Rakyat Dhukutan) dalam pembelajaran BIPA.

\section{METODE}

Metode yang digunakan dalam penelitian ini yaitu metode deskriptif kualitatif. Teknik pengumpulan data dilakukan melalui observasi, wawancara, analisis dokumen, dan FGD. Adapun nara sumbernya adalah ketua desa, tokoh-tokoh adat, guru, dinas pendidikan, dan 
masyarakat Desa Nglurah Tawangmangu Karanganyar. Analisis datanya menggunakan model analisis interaktif yang meliputi reduksi data,penyajian data, serta penarikan kesimpulan dan verifikasi.

\section{HASIL DAN PEMBAHASAN}

Kebudayaan identik dengan kesenian, upacara-upacara tradisional, cerita rakyat atau legenda serta kesusastraan yang melatarbelakanginya. Salah satu contoh kebudayaan yang melekat pada masyarakat Nglurah Tawangmangu yaitu Upacara Adat Dhukutan. Upacara Dhukutan merupakan upaca yang sudah lama dilakukan secara rutin oleh warga Dusun Nglurah.

Kata Dhukutan berasal dari kata Dukut, merupakan salah satu nama dari wuku Jawa yang berjumlah 28. Dhukutan dilaksanakan setiap 210 hari atau 7 bulan sekali, tepatnya pada hari Selasa Kliwon wuku Dukut. Nama wuku ini dipercaya diambil dari nama anak seorang tokoh bernama Dewi Shinta yang kawin dengan anaknya sendiri yang bernama Watugunung. Cerita ini merupakan cerita versi Airlangga karena Candi Menggung yang berada di Dusun Nglurah merupakan rangkaian dari Candi Sukuh dan Candi Cetha yang didirikan pada masa Airlangga. Candi Menggung diyakini sebagai tempat persembunyian Airlangga saat melarikan diri ke Wonogiri beserta pengikutnya [6].

Setiap dilaksanakan upacara Dhukutan, Warga Dusun Nglurah selalu membuat sesaji sesuai dengan aturan-aturan dalam proses pembuatannya. Jika aturan ini dilanggar, maka bisa menimbulkan bahaya bagi diri sendiri, keluarga, maupun seluruh warga dusun tersebut.

Pada dasarnya pelaksanaan tradisi ini adalah sebagai wujud ungkapan rasa syukur warga terhadap Yang Maha Kuasa atas karunia yang dilimpahkan kepada mereka. Sebagai bentuk rasa syukur atas kesehatan, kesejahteraan, keberkahan yang telah mereka terima.

Ada cerita rakyat yang melatarbelakangi dilaksanakannya Upacara tradisi Dhukutan, yaitu cerita Narotama. Siapakah Narotama itu? Narotama adalah seorang Patih Raja Airlangga dari Kahuripan. Ia dikenal sebagai tokoh sakti yang menyelamatkan Raja Airlangga dari serbuan tentara Wora Wari. Sepeninggalnya Narotama, makam Narotama oleh masyarakat dikeramatkan karena keberhasilan Narotama dalam menyelamatkan Airlangga. Narotama dikenal dengan nama Kyai Menggung.

Berikut ini adalah Cerita Narotama (Cerita Rakyat Dhukutan) yang melatarbelakangi diselenggarakannya Upacara Dhukutan.

Cerita diawali ketika Airlangga meninggalkan Desa Nglurah menuju Sukuh. Selanjutnya, Airlangga kembali ke Kediri bersama pengikutnya, kecuali Narotama dan beberapa anak buahnya. Sepeninggal Airlangga, Narotama dan beberapa pengikutnya menetap di Desa Nglurah. Di tempat itu, Narotama dan mutid-muridnya hanya mengonsumsi jagung. Ia mengajari murid-muridnya cara bercocok tanam jagung dan menyarankan penduduk setempat untuk bertanam jagung karena daerah itu hanya bisa ditanami dengan tanaman tersebut. Tanaman inilah yang kemudian menjadi makanan pokok penduduk Desa Nglurah.

Karena kearifan dan jiwa kepemimpinanannya Narotama kemudian digelari Kyai Menggung (Tumenggung). Pada masa itu, desa yang ditinggali Kyai Menggung dan pengikutnya mengalami kecukupan pangan. Padahal, sebelumnya Desa Nglurah (Kidul) dikenal sebagai desa miskin dan langka pangan. Saat itu, bahan pangan melimpah dan semua warga hidup sehat sejahtera. Bahkan ketika kemarau pun penduduk tidak kekurangan pangan karena hasil panen jagung tahan disimpan beberapa lama. Hal ini berbeda dengan kondisi daerah lain yang penduduknya kekurangan pangan sehingga banyak penduduk yang meninggal. 
Sementara itu, di bagian Desa Nglurah yang lain (Nglurah Lor) ada seorang wanita yang bernama Ni Rasa Putih. Dia adalah wanita dari daerah itu yang mempunyai perwatakan usil, nakal, dan suka berulah, namun dianggap sakti. Berbeda sekali dengan Kyai Menggung yang mempunyai sifat baik, santun, bijaksana, serta berwibawa. Ni Rasa Putih dan pengikutnya suka mempengaruhi dan melarang penduduk agar tidak mengikuti ajaran Kyai Menggung, termasuk menanam jagung.

Kemudian tersiar kabar daerah kekuasaan Ni Rasa Putih dilanda wabah penyakit. Banyak warga yang meninggal, bahkan bisa dikatakan "jika pagi sakit, sore mati" atau "sore sakit, pagi mati". Semua itu dipercaya sebagai kutukan karena tidak menaati ajaran Kyai Menggung. Padahal secara logika, daerah tersebut setelah tidak menanam jagung dan beralih menanam padi, hasilnya tidak baik. Kalau tanaman pangan gagal, berarti penduduk kekurangan makan dan kelaparan. Ini tentu mengakibatkan kondisi tubuh warga lemah sehingga gampang terkena berbagai penyakit.

Karena itu, Kyai Menggung dan Ni Rasa Putih menjadi musuh bebuyutan. Bertahun-tahun, kedua tokoh itu bersama murid-muridnya terlibat dalam perselisihan, tak jarang terjadi adu fisik. Bahkan beberapa kali antara keduanya pun terjadi perang tanding. Tidak ada yang kalah dan yang menang.

Namun perseteruan tersebut berakhir damai setelah keduanya menikah dan menjadi suami istri. Kemudian Ni Rasa Putih dikenal dengan nama Nyai Menggung. Pernikahan antara Kyai Menggung dan Nyai Menggung terjadi pada Wuku Dhukut, tepatnya hari Selasa Kliwon. Inilah yang melatarbelakangi diadakannya upacara Dhukutan. Dalam upacara Dhukulan ini terdapat sebuah upacara bernama Tawuran, yaitu saling melempar sesaji yang berupa nasi jagung. Upacara Tawuran ini melambangkan permusuhan antara Kyai Menggung dan Ni Rasa Putih yang kemudian berakhir damai.

Untuk lebih mempermudah serta menarik minat pemelajar BIPA memahami cerita rakyat Dhukutan, maka cerita tersebut digambarkan ke dalam bentuk komik. Berikut ini adalah cuplikan singkat komik berdasarkan Cerita Narotama [7].
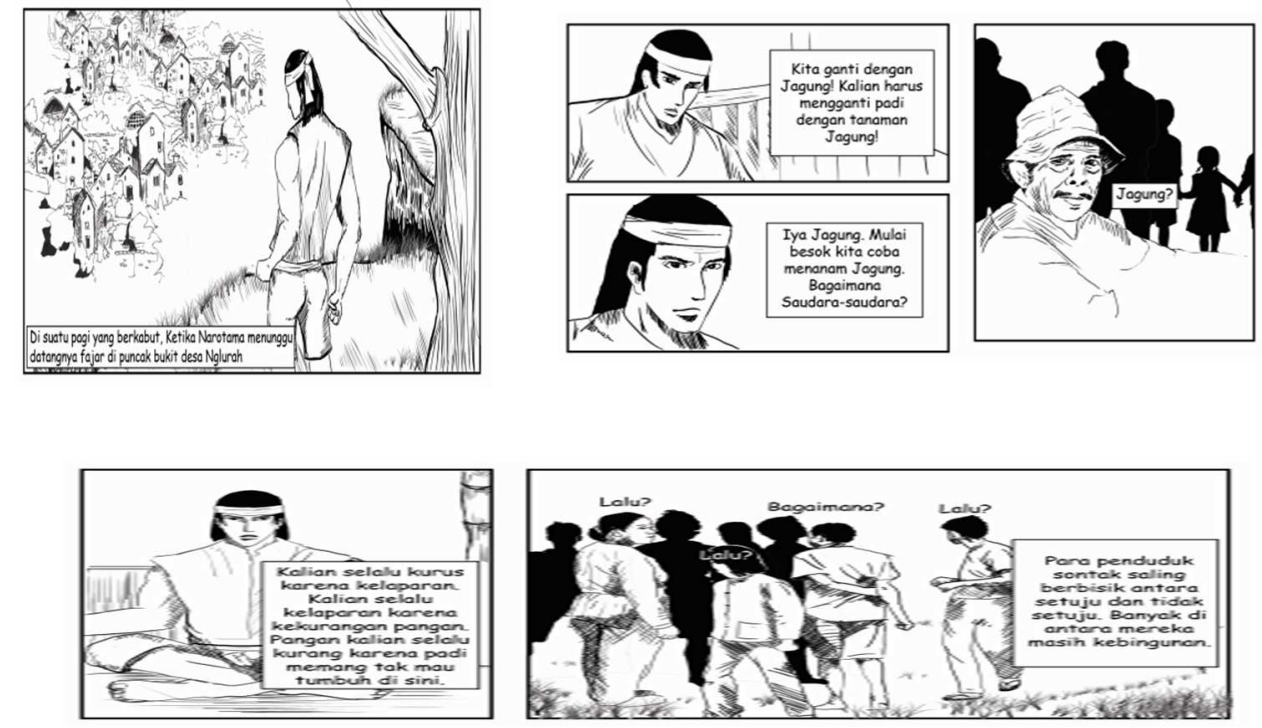



Dalam komik tersebut digambarkan tentang usaha Narotama untuk mengajak warga Nglurah Lor mau menanam jagung. Meskipun sebelumnya warga banyak yang meragukan hasilnya, akhirnya mereka mengikuti saran Narotama untuk menanam jagung. Selang beberapa lama kemudian, mereka bersuka cita bisa memanen jagung dengan kualitas jagung yang sangat baik.

Sebelum komik dimanfaatkan sebagai media pembelajaran, perlu dilihat kembali apakah komik tersebut layak dan cocok dimanfaatkan oleh pemelajar BIPA. Adakah pesan moral yang ingin disampaikan penulis kepada pembaca melalui komik tersebut. Nilai pendidikan karakter yang ditemukan di dalam komik tersebut di antaranya kepedulian terhadap lingkungan, kepemimpinan yang adil dan bijaksana, dan sifat senang memaafkan.

Penyampaian pesan moral melalui media komik diharapkan dapat dapat mempermudah dan menghibur pemelajar BIPA untuk mempelajari tentang keanekaragaman budaya Indonesia, salah satunya dengan mempelajari cerita rakyatnya. Dengan mempelajari dan mengenal cerita rakyatnya terlebih dahulu melalui komik, diharapkan pemelajar BIPA juga akan tertarik untuk mengenal lebih jauh upacara tradisionalnya.

Menurut [8], komik adalah suatu bentuk kartun yang mengungkapkan karakter dan memerankan suatu cerita dalam urutan yang erat dihubungkan dengan gambar yang dirancang untuk menghibur pembaca. Komik dapat mempermudah siswa dalam belajar. Hal ini relevan dengan pernyataan [9] yang menyatakan bahwa media komik merupakan salah satu bentuk sumber belajar yang dapat membantu siswa dalam belajar. Media komik dapat digunakan dalam proses pembelajaran dua arah, yaitu sebagai alat bantu mengajar dan sebagai media belajar yang dapat digunakan sendiri oleh siswa. Sependapat dengan hal tersebut, [8] menyatakan bahwa media komik dapat mendorong dan dapat membangkitkan minat siswa pada pembelajaran. Komik dapat membantu mereka dalam mengembangkan kemampuan berbahasa, berkegiatan seni, bercerita, dramatisasi, membaca, menulis, melukis, menggambar serta membantu mereka dalam menafsirkan dan mengingat isi materi bacaan dari buku teks. Buku-buku komik maupun buku gambar dapat dimanfaatkan secara secara efektif oleh guru-guru dalam usaha menimgkatkan minat, mengembangkan perbendaharaan kata-kata dan keterampilan membaca.

Dari penelitian yang telah dilakukan oleh [10] disimpulkan bahwa ada pengaruh yang signifikan dengan adanya penggunaan media komik terhadap peningkatan hasil belajar sejarah dan besarnya taraf signifikansi pengaruh penerapan media komik adalah sebesar 0,61. Dari hasil penelitiannya [10] menyimpulkan beberapa kelebihan media komik jika dipakai dalam pembelajaran, yaitu bisa memotivasi siswa karena berupa gambar, sifatnya lebih permanen, bisa digunakan siswa sebagai perantara untuk lebih senang membaca, serta sifatnya yang populer sehingga tidak membosankan. 
Komik bisa meningkatkan kompetensi siswa. Hal ini relevan dengan hasil penelitian yang menyatakan bahwa pemakaian komik Jepang sebagai alat belajar dapat meningkatkan kompetensi terjemahan siswa,pengetahuan budaya,dan motivasi mereka [11]. [9] juga menyatakan bahwa media komik sains ini dapat meningkatkan prestasi belajar. Namun dalam pemanfaaatannya diperlukan kerja sama antara guru, sekolah,dan pihak lain. Dalam pelaksanaannya, pemanfaatan media komik sains memerlukan biaya tambahan bila dibandingkan dengan pembelajaran konvensional. Adapun hasil penelitian [12] menemukan bahwa pemanfaatan komik dapat mengembangkan kosa kata dan menumbuhkan motivasi membaca serta dapat mengatasi hambatan linguistik dalam membaca materi yang otentik. Oleh karena itu aspek komik dan budaya sangat penting dalam pembelajaran BIPA [13][14].

\section{SIMPULAN}

Cerita Narotama yang merupakan mitos dilaksanakannya Upacara Tradisional Dhukutan sangat menarik untuk diketahui pemelajar BIPA. Cerita rakyat merupakan bagian dari kebudayaan yang penting untuk dilestarikan. Pemanfaatan media komik dengan materi cerita rakyat (Cerita Narotama) diharapkan bisa mempermudah dan memotivasi pemelajar BIPA untuk mempelajarinya.

\section{REFERENCES}

[1] Badan Bahasa, "Bahasa Indonesia bagi Penutur Asing (BIPA)," 2019. [Online]. Available: http://www.badanbahasa.kemdikbud.go.id/lamanbahasa/info_bipa, 2019.

[2] Koentjaraningrat, "Pengantar Ilmu Antropologi," Jakarta: Rineka Cipta, 2009.

[3] F. Haryadi, "Nilai Kearifan Lokal dalam Upacara Adat Ritus Tiwu Panganten Di Kecamatan Babakan Kabupaten Cirebon,” (Analisis Strukt., vol. 04, no. 02, 2013.

[4] D. N. Muliasari, "Nilai Kearifan Lokal dalam Upacara Adat Ritus Tiwu Panganten di Kecamatan Babakan Kabupaten Cirebon,” (Analisis Strukt., vol. Jurnal Pen, no. 11, p. 37, 2019.

[5] Andayani, "Pertemuan Ilmiah Bahasa dan Sastra Indonesia (PIBSI)," in Integrasi Model Pemahaman Budaya Lokal dalam Pembelajaran Bahasa Indonesia bagi Penutur Asing dengan Pendekatan Integratif, 2016, p. XXXVIII.

[6] E. Purwantiningsih, "Persepsi dan Partisipasi dalam Pelaksanaan Tradisi Dhukutan dan Dampaknya bagi Masyarakat Dusun Nglurah Kelurahan Tawangmangu Kecamatan Tawangmangu Kabupaten Karanganyar," Universitas Muhammadiyah Surakarta, 2010.

[7] Budaya Jawa, "Narotama, Patih Penyelamat Raja Airlangga," 2019. [Online]. Available: https://budayajawa.id/narotama-patih-penyelamat-raja-airlangga/. [Accessed: 14-Nov-2019].

[8] N. S. dan Ahmat Rivai, "Media Pengajaran," Bandung: Sinar Baru Algesindo, 2005.

[9] A. D. Saputra, "Aplikasi Komik sebagai Media," vol. 05, no. ISSN 2088-3390, 2015, p. 01.

[10] Prasetyono dkk, "Pengaruh Penggunaan Media Komik terhadap Peningkatan Hasil Belajar Sejarah," (Jurnal Pendidik. dan Penelit. Sejarah), vol. 03, no. 06, 2015.

[11] H. Furuhata-Turner, "Use of Comics Manga as a Learning Tool to Teach Translation of Japanese," J. Lang. Teach. Learn., vol. 2, pp. 72-83, 2013.

[12] I. Cimermanova, "Using Comics with Novice EFL Readers to Develop Reading Literacy," in In International Conference on New Horizons in Education, 2014, vol. INTE 2014.

[13] K. Saddhono, "Cultural and Social Change of Foreign Students in Indonesia: The 
Influence of Javanese Culture in Teaching Indonesian to Speakers of Other Languages (TISOL)," in IOP Conference Series: Earth and Environmental Science, 2018, vol. 126, no. 1 .

[14] K. Saddhono, Suhartatik, Bagiya, Widodo, and H. Wahyono, "Learning vocabularies using multimedia-based Teaching Indonesian to Speakers of Other Languages (TISOL)," in Journal of Physics: Conference Series, 2019, p. 012108. 